PIERIK, R. L. M. (1990): Rejuvenation and micropropagation. In: NikKamp, H. J. J., VAN DeR Plas, L. H. W., VAN AARTRIJK, J. (eds). Progress in Plant Cellular and Molecular Biology. Proceeds of the VII ${ }^{\text {th }}$ Inter. Congress on Plant Tissue and Cell Culture, Amsterdam, Netherland, pp 91-101.

POETHIG, R. S. (1990): Phase change and the regulation of shoot morphogenesis in plants. Science 250: 923-930.

RAZIN, A. and A. D. RIGGS (1980): DNA methylation and gene function. Science, 210: 604-610.

SAS Institute, Inc. (2000): SAS/STAT User's Guide, Cary, NC, USA.
SCHAFFALITZKY DE MUCKADELL, M. (1959): Investigations on aging of apical meristems in woody plants and its importance in silviculture. Kandrup and Wunsch's Bogtrykkeri, København, pp 313-346.

SokAL, R. R. and F. J. RoHLF (1995): Biometry. WH Freeman and Company, New York, USA, 887p.

Valledor, L., R. Hasbún, M. Meijon, J. L. Rodriguez, E. Santamaria, M. Viejo, M. Berdasco, I. Feito, M. F. Fraga, M. J. CANAL and R. Rodriguez (2007): Involvement of DNA methylation in tree development and micropropagation. Plant Cell Tissue and Organ Culture 91: 75-86.

\title{
Efficiencies of Clonally Replicated and Seedling Testing for Spruce Breeding and Deployment Strategies
}

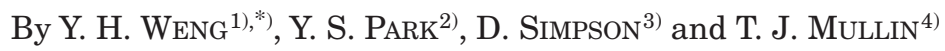 \\ (Received $18^{\text {th }}$ February 2009)
}

\begin{abstract}
Genetic gains based on a genetic test using clonal replicates were compared to those based on a test using seedlings at the same gene diversity and testing effort levels using POPSIM ${ }^{\mathrm{TM}}$ Simulator. Three testing and deployment strategies targeting for white spruce (P. glauca [Moench] Voss) and black spruce (P. mariana (Mill.) B.S.P.) in New Brunswick were compared: seedling test with clonal seed orchard deployed as seedlings (CSO_ST), clonally replicated test with clonal seed orchard deployed as seedlings (CSO_CRT), and clonally replicated test deployed as a clone mix (MVF). The breeding populations (BP) were formed by balanced within-family selection and the production populations (PP) were selected by strong restriction on relatedness, i.e., no parent in common. Compared to the seedling
\end{abstract}

1) New Brunswick Department of Natural Resources, Kingsclear Forest Nursery, Island View, NB, Canada, E3E $1 \mathrm{G} 3$.

2) Natural Resources Canada, Canadian Forest Service-Canadian Wood Fibre Centre, P.O. Box 4000, Fredericton, NB, Canada, E3B 5P7.

3) Natural Resources Canada, Canadian Forest Service-Atlantic Forestry Centre, P.O. Box 4000, Fredericton, NB, Canada, E3B 5 P7.

$\left.{ }^{4}\right)$ BioSylve Forest Science NZ Limited, 45 Korokoro Road, Lower Hutt 5012, New Zealand.

*) Corresponding author: Telephone 506-444-5125, Fax 506-4444917. E-Mail: $\underline{\text { Yuhui.Weng@ggnb.ca }}$ test, the clonally replicated test resulted in faster accumulation of additive effects but quicker loss of additive variance in the $\mathrm{BP}$, and this is particular true in the case of lower narrow-sense heritability or less non-additive genetic variance. The quicker loss in $\mathrm{BP}$ additive variance was overcompensated for by its faster accumulation in $\mathrm{BP}$ additive effect, resulting in higher gain in the clonally replicated test based PPs. Compared to the CSO_ST, the gain superiority of the CSO_CRT increased with generations, decreasing narrow-sense heritability or reducing the amount of non-additive variance. Implementing MVF was the most effective in terms of gain in most simulated cases and its superiority over the CSO_ST increased with generations, decreasing narrowsense heritability, or increasing non-additive genetic variance. Overall results demonstrated significant advantages of using clonally replicated test both for BP advancement and PP selection in most of the scenarios, suggesting that clonally replicated test should be incorporated into current spruce breeding strategies.

Key words: breeding population, production population, multivarietal forestry, clonal seed orchard, genetic gain, status number.

\section{Introduction}

Most tree breeding strategies have adopted a recurrent selection scheme to generate successive generations of a breeding population (BP). Superior phenotypes are selected to form a BP and are inter-mated and their 
progenies planted in genetic tests. The best genotypes in the tests are selected to form the advanced BP, and a subset of the BP forms a production population (PP). There are several options for PPs, the most important ones being harvesting seeds from clonal seed orchards and vegetatively deploying varieties (clones) in mixture, referred to as multi-varietal forestry (MVF) in this study.

Genetic tests are crucial to the success of tree improvement efforts and can be established either using seedlings or clonal replicates of genotypes. As forward selection from a seedling test is based on an individual's genetic value, predicted from a single phenotypic observation, selection efficiency is generally poor, especially when individual narrow-sense heritability is low (FALCONER and MACKAY, 1996; DANUSEVIČIUS and LINDGREN, $2002 \mathrm{a}, 2002 \mathrm{~b})$. In contrast, clonally replicated tests, where each genotype is cloned and planted across multiple environments, can be very efficient at separating environmental from genetic effects, thus enhancing selection efficiency (LIBBY, 1964, 1969; BURDON and SHelbourne, 1974; SHAW and Hood, 1985; Russell and Loo-Dinkins, 1993; DANUSEvičIUs and LindGREN, 2002a, $2002 \mathrm{~b})$. Although the benefits of using clonal replicates are well recognized, relatively few studies have compared differences in gain between the two testing types for BP advancement (SHELBOURNE, 1992; DANUSEVIČIUS and Lindgren, 2002a, Shelbourne et al., 2007). These studies demonstrated that breeding strategies based on clonal testing could obtain higher gain than those based on seedling testing. Operationally, the most successful example is Norway spruce ( $P$. abies (L.) Karst.) in Sweden where clonally replicated test has been demonstrated to be a robust and efficient method to advance breeding cycles (Rosvall et al., 1998).

The ultimate goal of tree improvement is to increase gain in PPs. Comparisons in PP gain between tests of clonal replicates and of seedlings are few. MATHESON and LINDGREN (1985) compared long-term gain from clonal deployment with that from the clonal seed orchard option and found that, even when dominance variance is zero, considerable extra gain (in genetics and time) could be obtained by the clonal option over the orchard option. Empirical studies for black spruce $(P$. mariana [Mill.] B.S.P.) (Mullin et al., 1992; Mullin and PARK, 1994; NBTIC, 1999) and white spruce ( $P$. glauca [Moench] Voss) (WENG et al., 2008) also demonstrated the considerable efficiency in capturing gain from implementing clonal options. Comparisons in the above studies, however, were made on the basis of the same genetic test of clonal replicates, and did not consider genetic diversity simultaneously.

Black spruce and white spruce are the most important commercial species in New Brunswick (NB), Canada, where approximately 30 and 15 million seedlings, respectively, are planted annually. Currently, a strategy of clonal seed orchard paired with seedling test is practiced in NB, although strategies incorporating clonal replicates have been proposed for both species (MORGENSTERN and PARK, 1991; PARK et al., 1993; MULLIN, 1994). With recent developments in somatic embryogenesis (PARK et al., 1998) and more genetic information becom- ing available for both species (MULLIN et al., 1992; MUllin and PARK, 1994; Weng et al., 2008), the New Brunswick Tree Improvement Council (NBTIC) members are becoming interested in incorporating clonally replicated test into the current breeding strategy. The basic question of "what are the relative efficiencies of clonally replicated test over seedling test for both breeding and production populations" has to be answered. To compare efficiencies between the two testing types, both the genetic diversity and testing effort should be kept at the same levels. Thus, the objective of this study was to compare gains in both black and white spruce breeding and production populations between selections made in a clonally replicated test and those made in a seedling equivalent at the same diversity level and at the same testing effort using computer simulation.

\section{Methods}

A hypothetical closed BP was simulated by a stochastic parametric model using POPSIM ${ }^{\mathrm{TM}}$ (MULLIN and PARK, 1995). The model structure, genetic theory and underlying assumptions for this tool have been described in detail elsewhere (MULLIN and PARK, 1995; ROSVALL et al., 1998). In summary, the additive breeding value $(A)$ for an individual in the founder population was sampled from a normal distribution $N\left(\mu, V_{\mathrm{A}}\right)$, where $V_{\mathrm{A}}$ is the variance due to additive effects. The $A$ of each offspring was obtained as the average of the parents $A_{\mathrm{f}}$ and $A_{\mathrm{m}}$ plus a random Mendelian deviation sampled from $N\left(0,0.5 V_{\mathrm{A}}\left(1-F_{\mathrm{fm}}\right)\right)$, where $F_{\text {fm }}$ is the average of $F_{\mathrm{f}}$ and $F_{\mathrm{m}}$, which are the inbreeding coefficients of the female and male parents, respectively, obtained from pedigree analysis. The dominance effects $(D)$ for full-sib families were sampled from a normal family distribution with variance equal to $N\left(0,0.75 V_{\mathrm{D}}\left(1-F_{\mathrm{fm}}\right)\right)$ and with a family mean dominance effect sampled from $N\left(0,0.25 V_{\mathrm{D}}\right)$, where $V_{\mathrm{D}}$ is the variance due to dominance effects. The epistatic effects $(I)$ were sampled from $N\left(0, V_{\mathrm{I}}\right)$, and the environmental effects $(E)$ were sampled from $N\left(0, V_{\mathrm{E}}\right) . V_{\mathrm{I}}$ and $V_{\mathrm{E}}$ are epistatic and environmental variances, respectively. The phenotypic value of an individual was simulated as a sum of its $A, D, I$ and $E$. Genetic diversity was expressed as status number $\left(N_{\mathrm{S}}\right)$, defined as $N_{\mathrm{S}}=0.5 / \theta$, where $\theta$ is the group coancestry (COCKERHAM, 1967) of the selections of the population (LINDGREN et al., 1996).

Two testing methods (clonal replicate and seedling) and two deployment methods (clonal seed orchard and clonal mixture), which result in following three strategies, were evaluated in this study: (1) CSO_ST: selections were made based on a seedling test and improved materials were deployed as seedling via clonal seed orchard approach; (2) CSO_CRT: selections were made based on a clonally replicated test and improved materials were deployed as seedling via clonal seed orchard approach; and (3) MVF: selections were made based on a clonally replicated test and improved materials were deployed as a clone mixture.

The initial BP (=100 unrelated trees) was the same for all the strategies. The strategies incorporate 'dynamic' time schedules for activities such as seed orchard 
establishment, genotype selection, and establishment of genetic tests. The time schedule for each strategy was determined following the breeding strategy for spruce species in Eastern Canada (FowLER, 1986), with adjustments made in timing to reflect shortened periods for flower stimulation technologies and new developments in somatic embryogenesis technique. The initial BP of 100 unrelated parent trees was randomly assigned into 5 sublines with 20 trees each. Non-assortative, doublepair mating (each parent is mated with two other parents) was applied within sublines to create a total of 100 crosses (full-sib families), which were then planted in a genetic test with a total of 15,000 trees in each breeding cycle. The genetic tests of clonal replicates and of seedling were assumed to be established at the same testing effort, i.e., the same family size and the total planted trees. When the test was established with seedlings, 150 genotypes were tested for each cross; when the test was established with clonal replicates, 30 genotypes (clones) from each cross were tested with 5 ramets per clone. Selection was applied to a single polygenic trait (or an index of several traits) in a diploid organism. A combined index where family and individual tree or clone values are weighted by their respective heritabilities was calculated according to MULLIN and PARK (1995) for each progeny or clone and used as the selection criterion. The BP for the next cycle was formed by within-family selection, e.g., selecting the best individual genotype from each cross. Selection of the 20 genotypes for the clonal seed orchard and MVF was made uniformly over sublines and restricted so as to have no parent in common, to determine possible gains under the maximum level of $N_{\mathrm{S}}$. The BP of each simulation was managed through 5 recurrent breeding cycles. The details for breeding, testing, and deployment are given in Table 1.

In all simulations, three parameters: the population mean (= 100 units), the standard rate of inbreeding depression $(=0)$, and the $V_{\mathrm{A}}$ (= 100 units), were kept constant, while other parameters $\left(V_{\mathrm{D}}, V_{\mathrm{I}}\right.$ and $\left.V_{\mathrm{E}}\right)$ were varied to represent an assortment of narrow-sense individual heritabilities $\left(h^{2}\right)$ and genetic architectures (defined as the ratio among $V_{\mathrm{A}}: V_{\mathrm{D}}: V_{\mathrm{I}}$ ). The $h^{2}$ (ranging from 0.05 to 0.5 ) was varied by changing $V_{\mathrm{E}}$ while keeping the genetic variances constant. The genetic architecture was varied by changing $V_{\mathrm{D}}$ or $V_{\mathrm{I}}$ while keeping $h^{2}$ constant through changes to its associated $V_{\mathrm{E}}$. The $V_{\mathrm{D}}$ and $V_{\mathrm{I}}$ were assumed to be in the range between zero and $V_{\mathrm{A}}$, which covers the range of $V_{\mathrm{D}}$ and $V_{\mathrm{I}}$ likely to occur in spruce breeding programs in NB conditions (MULLIN et al., 1992; Mullin and PARK, 1994; Weng et al., 2007, 2008). Genotype by environment interaction was assumed to be negligible, which seems reasonable in $\mathrm{NB}$ as the whole province is treated as one breeding zone for

Table 1. - Schedule for selection of a breeding population (BP) and production populations (PP) for white spruce and black spruce in New Brunswick.

\begin{tabular}{|c|c|c|c|c|}
\hline \multirow[b]{2}{*}{ Gen. } & \multirow[b]{2}{*}{ Year $^{1}$} & \multirow{2}{*}{$\begin{array}{l}\text { Breeding population } \\
\text { management plan }\end{array}$} & \multicolumn{2}{|c|}{ Production population $^{2}$} \\
\hline & & & $\mathrm{CSO}$ & MVF \\
\hline \multirow[t]{3}{*}{0} & 0 & $\begin{array}{l}100 \text { selections } \\
(5 \text { sublines } \times 20 \text { trees per subline })\end{array}$ & $\begin{array}{l}\text { CSO establishment } \\
\text { ( } 20 \text { clones) }\end{array}$ & \\
\hline & $5-8$ & $\begin{array}{l}\text { crossing } \\
\text { (in total } 100 \text { crosses; } \\
\text { random, double-pair mating) }\end{array}$ & $\begin{array}{l}\text { CSO start to } \\
\text { provide seed }\end{array}$ & \\
\hline & 9 & $\begin{array}{l}\text { establishing genetic tests } \\
(N=15,000 ; \\
\text { if seedling, } 150 \text { trees per cross } \\
\text { planted; if clonal replicates, } \\
30 \text { clones per cross with } 5 \\
\text { ramets per clone planted) }\end{array}$ & & \\
\hline 1 & 20 & $\begin{array}{l}\text { evaluation and selection } \\
\text { (100 trees for next } \\
\text { breeding population; } \\
\text { within-family selection) }\end{array}$ & $\begin{array}{l}\text { CSO establishment } \\
(20 \text { clones })\end{array}$ & $\begin{array}{l}\text { MVF } \\
\text { ( } 20 \text { clones) }\end{array}$ \\
\hline & 25 & & $\begin{array}{l}\mathrm{CSO} \\
\text { start to provide seed }\end{array}$ & \\
\hline
\end{tabular}

\footnotetext{
${ }^{1}$ based on spruce species in New Brunswick.

${ }^{2} \mathrm{CSO}$, clonal seed orchard; MVF, multi-varietal forestry.
} 
Table 2. - Parameters used for simulation of a founder population of 100 unrelated trees, which was divided into five, 20 -tree sublines.

\begin{tabular}{lll} 
Parameters & Baseline & Alternatives \\
\hline Mean of trait & 100 & \\
Standard rate of inbreeding depression & 0 & \\
Additive variance $\left(V_{\mathrm{A}}\right)$ & 100 & $0-100$ \\
Dominance variance $\left(V_{\mathrm{D}}\right)$ & 25 & $0-100$ \\
Epistatic variance $\left(V_{\mathrm{I}}\right)$ & 0 & $75-1875$ \\
Environmental variance $\left(V_{\mathrm{E}}\right)$ & 375 & $0.05-0.5$ \\
Narrow-sense heritability $\left(h^{2}\right)$ & 0.2 & \\
\hline
\end{tabular}

spruce species (Fowler, 1986). As somatic embryogenesis was assumed to be the method to produce clones, variances associated with cloning were also ignored. The combination of $V_{\mathrm{A}}: V_{\mathrm{D}}: V_{\mathrm{I}}=100: 25: 0$ and a $h^{2}=0.2$, representing the most possible values for spruce species in NB conditions (WENG et al., 2008), was chosen as the baseline parameter scenario. Details for parameter settings are given in Table 2.

Simulations were made by modifying one parameter at a time. For each generation, the simulations tracked changes in $A, V_{\mathrm{A}}$, and $N_{\mathrm{S}}$ in the $\mathrm{BP}$ and gain and $N_{\mathrm{S}}$ in the PPs. In each case, the interpretation was based on average result of 100 iterations. The stochastic variation in the parameters was described by the coefficient of variation for results from the simulation iterations of a given scenario.

The advantage of clonally replicated test over seedling test was expressed as relative efficiency. The relative efficiency in $\mathrm{BP} A$ (referred to as $R E_{\mathrm{A}}(B P)$ ) and $\mathrm{BP} V_{\mathrm{A}}$ (referred to as $R E_{\mathrm{V}_{\mathrm{A}}}(B P)$ ) were calculated as the difference between the clonally replicated test and seedling test and expressed as a percentage of the seedling test. The relative efficiency in gain for the CSO_CRT $\left(R E_{\mathrm{G}}\left(C S O \_C R T\right)\right)$ and the MVF $\left(R E_{\mathrm{G}}(M V F)\right)$ were calculated as a percentage difference, relative to gain achievable from the CSO_ST, the strategy currently practiced in NBTIC programs.

\section{Results}

Comparisons in gain and diversity for breeding population (BP) advancement

After 100 simulation runs, the coefficients of variation for the parameters of both tests were low, i.e., in generation 5 , the coefficients of variation were less than 1.9 and $15 \%$ for BP $A$ and $V_{\mathrm{A}}$, respectively. For both tests, the BP $A$ increased linearly, whereas BP $V_{\mathrm{A}}$ decreased exponentially over generations (data not shown). Despite the similar development trends, the clonally replicated test was more effective in enhancing the BP $A$. Under the baseline parameters, the BP $A$ for the clonal replicates increased 8 units per generation and reached 42 units after 5 generations, compared to only 6 units per generation and a total of 31 units for the seedling test. The faster accumulation in BP $A$ from the clonally replicated test was at a cost of losing $B P V_{\mathrm{A}}$ at a higher rate (i.e., after the $1^{\text {st }}$ cycle of selection the $\mathrm{BP} V_{\mathrm{A}}$ was reduced by $10 \%$ for the clonally replicated test, compared to only $6 \%$ for the seedling test) and over a longer period than that from the seedling test. Consequently, the $R E_{\mathrm{A}}(B P)$ were positive and relatively stable over generations, whereas the $\left.R E_{\mathrm{V}_{\mathrm{A}}}(B P)\right)$ were negative and decreased non-linearly over generations (Figure 1).

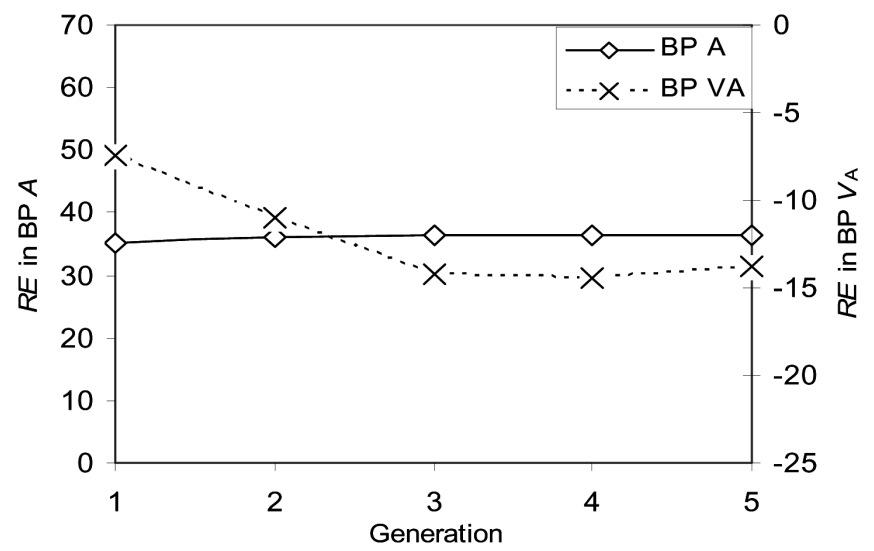

Figure 1. - Relative efficiency in breeding population additive effect $(R E$ in $\mathrm{BP} A)$ and variance $\left(R E\right.$ in $\left.\mathrm{BP} V_{\mathrm{A}}\right)$ based on a genetic test of clonal replicates compared to an equivalent test of seedlings according to the spruce breeding strategy (Table 1) and the baseline parameter scenario (Table 2). 
The $R E_{\mathrm{A}}(B P)$ and $R E_{\mathrm{V}_{\mathrm{A}}}(B P)$ varied with $h^{2}$ (Figure $2 a$ ). The $R E_{\mathrm{A}}(B P)$ decreased with increasing $h^{2}$; it was $65 \%$ when $h^{2}=0.05$ but was negligible when $h^{2}=0.5$. The $R E_{\mathrm{V}_{\mathrm{A}}}(B P)$ increased with increasing $h^{2}$ and the values were larger at the later generations. Introduction of non-additive genetic variance $\left(V_{\mathrm{NA}}\right)$ did not significantly affect the BP $A$ and $V_{\mathrm{A}}$ of the selections from the seedling test (data not shown) but showed a different pattern when the test was established using clonal replicates. The introduction of $V_{\mathrm{D}}$ decreased the $\mathrm{BP} A$ and increased $\mathrm{BP} V_{\mathrm{A}}$ for the clonally replicated test, thus resulting in a trend of decreasing $R E_{\mathrm{A}}(B P)$ but increasing the $R E_{\mathrm{V}_{\mathrm{A}}}(B P)$ with increasing $V_{\mathrm{NA}}^{\mathrm{A}}$ amount (Figure $2 b)$. The effects of introducing $V_{\mathrm{D}}$ on the $R E_{\mathrm{V}_{\mathrm{A}}}(B P)$ were more pronounced at later generations. $V_{\mathrm{I}}$ had a similar effect (Figure 2b). Consequently, the introduction of $V_{\mathrm{NA}}$ weakened the superiority of the clonally replicated test over the seedling test, as indicated by the decreased $R E_{\mathrm{A}}(B P)$, although this effect was partially offset by the lower rate of additional losing $\mathrm{BP} V_{\mathrm{A}}$. This was especially true when all $V_{\mathrm{NA}}$ was due to $V_{\mathrm{I}}$. However, even when $V_{\mathrm{I}}=V_{\mathrm{A}}$, selection from the clonally replicated test achieved $15 \%$ more BP $A$ than did the seedling test in each generation. Thus, the clonally replicated test was especially effective for BP advancement in the earlier generations, lower $h^{2}$ or less amount of $V_{\mathrm{NA}}$, yielding higher additional BP $A$ without losing too much BP $V_{\mathrm{A}}$ relative to the seedling test.
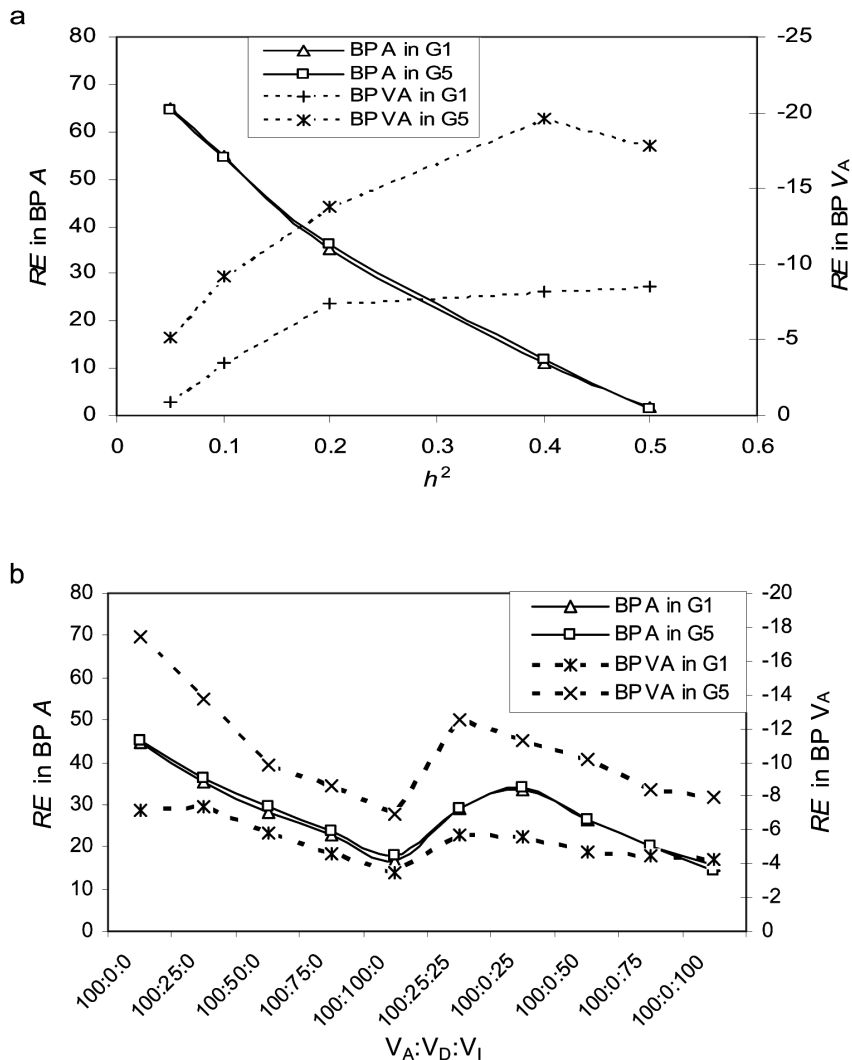

Figure 2. - Effects of (a) narrow-sense heritability $\left(h^{2}\right)$ and (b) genetic architecture $\left(\mathrm{V}_{\mathrm{A}}: \mathrm{V}_{\mathrm{D}}: \mathrm{V}_{\mathrm{I}}\right)$ on the relative efficiencies in breeding population additive effect $(R E$ in $\mathrm{BP} A)$ and variance $\left(R E\right.$ in $\left.\mathrm{BP} V_{\mathrm{A}}\right)$ in the $1^{\text {st }}(\mathrm{G} 1)$ and $5^{\text {th }}(\mathrm{G} 5)$ generations between a test of clonal replicates and an equivalent test of seedlings. Note that in (a) the $\mathrm{V}_{\mathrm{A}}: \mathrm{V}_{\mathrm{D}}: \mathrm{V}_{\mathrm{I}}=100: 25: 0$ and in (b) $h^{2}$ was kept at 0.2 .
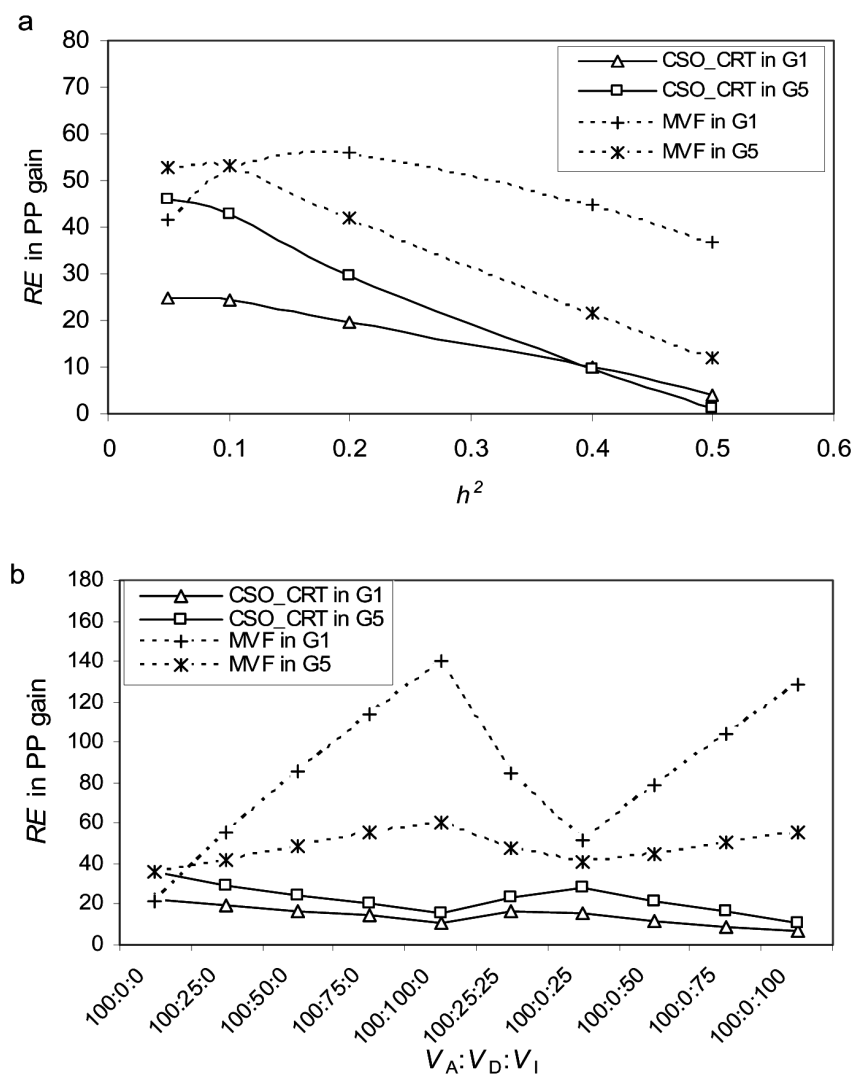

Figure 3. - Effects of (a) individual heritability $\left(h^{2}\right)$ and (b) genetic architecture $\left(\mathrm{V}_{\mathrm{A}}: \mathrm{V}_{\mathrm{D}}: \mathrm{V}_{\mathrm{I}}\right)$ on the relative gain advantages ( $R E$ in PP gain) in the $1^{\mathrm{st}}(\mathrm{G} 1)$ and $5^{\text {th }}$ (G5) generations of the CSO_CRT (clonally replicated test paired with clonal seed orchard approach) and MVF (clonally replicated test paired with clonal mix deployment) over the CSO_ST (seedling test paired with clonal seed orchard approach). Note that in (a) $\mathrm{V}_{\mathrm{A}}: \mathrm{V}_{\mathrm{D}}: \mathrm{V}_{\mathrm{I}}=100: 25: 0$ and in (b) $h^{2}$ was kept at 0.2 .

As a result of BP selection being strictly within family, the BP $N_{\mathrm{S}}$ were identical between the tests of clonal replicates and of seedlings, decreased from 100 to 29 over five breeding cycles. The BP $N_{\mathrm{S}}$ decreased exponentially and over $70 \%$ of its loss occurred in the first two generations.

\section{Comparisons in gain and diversity among the production populations (PPs)}

Genetic gain was higher for the CSO_CRT than the CSO_ST, but the $R E_{G}\left(C S O \_C R T\right)$ were affected over time by both $h^{2}$ or $V_{\mathrm{NA}}$. The $R E_{G}\left(C S O_{-} C R T\right)$ was higher at later generations when $h^{2}<0.4$, after that, it showed a reversal pattern (Figure $3 a$ ). This is because the $R E_{G}\left(C S O \_C R T\right)$ decreased with increasing $h^{2}$, and the decreasing rate was higher when $h^{2}>0.1$ or at later generations (Figure $3 a$ ). Under the baseline scenario (see Figure $3 a$ at $\left.h^{2}=0.2\right)$, the $R E_{G}\left(C S O \_C R T\right)$ increased from $20 \%$ in the $1^{\text {st }}$ generation to $30 \%$ in the $5^{\text {th }}$ generation. Compared to the CSO_ST, the extra gain from the CSO_CRT was negligible when $h^{2}$ approached 0.5. In parallel to the BP $A$ trend with genetic architecture (Figure $2 b$ ), the higher $V_{\mathrm{D}}$ resulted in a lower $R E_{G}\left(C S O \_C R T\right)$ and the decreasing rates were slightly higher in the later generations (Figure $3 b$ ). $V_{\mathrm{I}}$ acted sim- 
ilarly but had a smaller $R E_{G}\left(C S O_{-} C R T\right)$ when $V_{\mathrm{I}}=V_{\mathrm{D}}$ (Figure $3 b)$. Even when $V_{\mathrm{I}}=V_{\mathrm{A}}$, the $R E_{G}\left(C S O \_C R T\right)$ was higher than $11 \%$ after 5 generations. Overall the superiority of CSO_CRT over the CSO_ST was more pronounced at later generations, the lower $h^{2}$, or less amount of $V_{\mathrm{NA}}$.

Implementing MVF was always the most effective in capturing gain. Under the baseline parameter scenario, MVF achieved a $42 \%$ higher gain than the CSO_ST after five generations. Its superiority over the CSO_ST also varied with generation, $h^{2}$ and $V_{\mathrm{NA}}$ (Figure 3 ). The $R E_{G}(M V F)$ was higher at earlier generations with the exception of $h^{2}<0.1$ or $V_{\mathrm{NA}}=0$ and the differences between the generations increased with increasing $h^{2}$ or $V_{\mathrm{NA}}$ amount. The highest $R E_{G}(M V F)$ appeared at $h^{2}=0.2$ in the $1^{\text {st }}$ generation and at 0.1 in the $5^{\text {th }}$ generation (Figure 3a). As expected, the advantage of MVF over the CSO options became more pronounced when more $V_{\mathrm{D}}$ was present. After 5 generations, MVF achieved $60 \%$ higher gain than the CSO_ST option when $V_{\mathrm{D}}=V_{\mathrm{A}}$ (Figure $3 b) . V_{\mathrm{I}}$ showed a similar, but less pronounced effect (Figure $3 b$ ).

As PPs were selected uniformly across sublines under the strongest restriction on relatedness, i.e., no parent in common, the $N_{\mathrm{S}}$ were same among the PPs. The PP $N_{\mathrm{S}}$ decreased from 20 in the $1^{\text {st }}$ generation to about 15 at the $5^{\text {th }}$ generation.

\section{Discussion}

Simulation was done over five generations, not so much to predict actual gain but to compare relative efficiencies in gain between tests of clonal replicates and of seedlings for BP advancement and PPs. The selection methods and restrictions for the $\mathrm{BP}$ and PPs in this study were deliberately used so that $N_{\mathrm{S}}$ can be kept at the same levels between the tests. Compared to seedling test, clonal testing of the $\mathrm{BP}$ with a fixed number of trees per family results in fewer genotypes per family, but balanced within-family selection with one genotype per family or strong restricted selection (i.e., no parent tree in common) does not reduce $\mathrm{BP}$ or PP $N_{\mathrm{S}}$. Thus, the superiorities of clonally replicated test over its seedling equivalent reported here were advantageous at the same $N_{\mathrm{S}}$.

The balanced within-family selection for BP advancement is generally regarded as inefficient in short-term breeding, since it makes use of only half of the initial $V_{\mathrm{A}}$. Other studies have suggested applying family selection, multi-stage selection or selecting more individuals from the better families (WHITE et al., 2007) to maximize BP $A$, these greater exploitations of the additive variance involve a quicker loss of diversity, reducing longterm gain potential. For long-term breeding, balanced within-family selection seems to be a near-optimal strategy, even considering possible gain in PPs drawn from the BP (DANUSEVIČIUS and LINDGREN, 2002b; RosvalL and Mullin, 2003). Compared to the methods used in this study, there are advantages in creating a BP with assortative mating (i.e., positive assortative mating) and/or by allocating more resources to better parent trees (Rosvall and Mullin, 2003; LstibŮReK et al., 2004a, 2004b). Obviously, application of these modifications will result in changes in $\mathrm{BP} A$ and $V_{\mathrm{A}}$. However, these changes are shared by both testing types and will not significantly bias the main findings of this study.

The observed disparity in the BP $A$ between the testing types reflects the difference in selection precision and intensity. As discussed before, compared to a seedling test, an equivalent-sized clonally replicated test will reduce its selection intensity under a balanced within-family selection plan but will enhance selection precision by averaging the environmental noise, effectively increasing heritability (LIBBY, 1969; BURDON and SHELBOURNe, 1974; ShaW and Hood, 1985; Shelbourne, 1992; Russell and Loo-Dinkins, 1993; Rosvall and MulLIN, 2003). Results from this study suggest that the lower selection intensity for the clonally replicated test is overcompensated for by its higher selection precision, resulting in an enhanced BP $A$. Clonal mean based selection results in less $\mathrm{BP} V_{\mathrm{A}}$ among selections than does selection on phenotypic value. Accumulation of inbreeding will also affect genetic variance (FALCONER and MACKAY, 1996), but here accumulation of inbreeding was equally controlled in all scenarios by strict within-family selection. In operational programs, an even higher superiority in BP $A$ from clonally replicated test can be obtained. This is because the optimal BP size can be much smaller for a clonally replicated test based BP compared to an equivalent seedling test based one (DANUSEVIČIUS and LINDGREN, 2005). Thus, more testing resources can be relocated for testing effort for the clonally replicated test based breeding strategy.

Corresponding well with other studies, the $R E_{A}(B P)$ is roughly proportional to $h^{2}$ and the amount of $V_{\mathrm{NA}}$ (Figure 2). The $R E_{A}(B P)$ is minimal when $h^{2}$ exceeds 0.5 (DANuseviC̆IUs and LindGREN, 2002a; SHElbourne et al., 2007; Figure 2a), suggesting that clonally replicated test favours traits with $h^{2}$ less than 0.5. For most growth traits of spruce species in Eastern Canada, the $h^{2}$ is not likely to be higher than 0.25 (MULLIN et al., 1992; MULLIN and PARK, 1994; WENG et al., 2007, 2008), implying that additional BP $A$ will be high if a clonally replicated test is incorporated into the current NBTIC spruce programs. The erosion in superiority of the clonally replicated test by $V_{\mathrm{NA}}$ is due to lower clone-mean heritability and then a lower selection precision (ROSVALL et al., 1998; DANUSEVIČIUS and LINDGREN 2002a; Figure $2 b$ ). Since only additive genetic gain associated with breeding values and average allele effects is accumulated in the $\mathrm{BP}$, the $V_{\mathrm{NA}}$ does not significantly affect the seedling test efficiency (SHAW and HoOD, 1985; WHITE et al., $2007)$. Even at higher levels of $V_{\mathrm{NA}}$, i.e., $V_{\mathrm{D}}$ makes up to $300 \%$ of the $V_{\mathrm{A}}$, however, its adverse effects are still likely to be overcompensated for by greater selection precision from the clonally replicated test (BURDON and SHELBOURNE, 1974; DANUSEVIC̆IUS and LINDGREN, 2002a). In this study, the upper limit of $V_{\mathrm{NA}}$ was set to equal $V_{\mathrm{A}}$. In this case, selection from the clonally replicated test resulted in over $14 \%$ greater BP $A$ than that made from the seedling test at each generation (Figure $2 b$ ). Recent studies in partitioning genetic variance for spruce species in NB suggested that $V_{\mathrm{A}}$ would be far more important than $V_{\mathrm{NA}}$ for growth traits at 10 to 15 -years 
old (Mullin and PARK, 1994; NBTIC, 1999; WENG et al., 2008), suggesting that the undesirable effects on longterm spruce breeding resulting from $V_{\mathrm{NA}}$ should be small. Compared to $V_{\mathrm{D}}$, introduction of an equal amount of $V_{\mathrm{I}}$ resulted in less superiority of the clonally replicated test over its seedling equivalent in terms of BP $A$ (Rosvall et al., 1998; Figure 2b). This is because $V_{\mathrm{I}}$ is assumed to be within-family and its presence reduces BP $A$ more and $V_{\mathrm{A}}$ less than that from an equal amount of $V_{\mathrm{D}}$.

Genetic gain captured by PPs from a long-term BP consists of two components: (1) the BP A from undergoing cycles of selection and testing and (2) the potential utilization of BP $V_{\mathrm{A}}$ (MATHESON and LINDGREN, 1985). Thus, compared with seedling test, clonally replicated test generated a potential for additional PP gain due to its higher BP $A$, but this potential may be diluted by its resulting lower BP $V_{\mathrm{A}}$. This partly explains why the $R E_{G}\left(C S O \_C R T\right)$ (Figure 3a) is lower compared to the respective $R E_{A}(B P)$ (Figure $2 a$ ). The meaningful, positive $R E_{G}\left(C S O \_C R T\right)$ suggests that the loss in PP gain due to the faster erosion in $\mathrm{BP} V_{\mathrm{A}}$ is overcompensated for by the increase from the quicker $\mathrm{BP} A$ accumulation in the clonally replicated test, and this is especially true at later generations, lower $h^{2}$ or less $V_{\mathrm{NA}}$ (MATHESON and LINDGREN, 1985; Rosvall et al., 1998; Figure 3). This is an encouraging result and implies that clonally replicated test can have a major impact on the efficiency of breeding programs, even when all genetic variance is due to additive effects or clones are not for deployment of operational planting stock. As expected, practicing MVF was always the most effective in terms of gain, although its superiority decreased over generations in most of the $h^{2}$ simulated (Figure $3 a$ ), a result of constant non-additive effects over generations. One surprising finding was that the superiority of MVF over the CSO_ST maximized at $h^{2}=0.1 \sim 0.2$ (Figure $3 a$ ). Even if the case of $h^{2}=0.5$ and $V_{\mathrm{A}}: V_{\mathrm{D}}: V_{\mathrm{I}}=100: 25: 0$, MVF could obtain $12 \%$ more gain than the CSO_ST, a result of utilizing $V_{\mathrm{NA}}$ (Figure $3 a$ ). The higher the $V_{\mathrm{NA}}$ effects, the greater are the advantages of MVF over the orchard options (MATHESON and LINDGREN 1985; Figure $3 b$ ).

In practice, the actual benefits from implementing MVF can be further enhanced, since more related and fewer clones can be accepted in a clone mix for MVF than is possible for an orchard, where related or limited clones would increase the proportion of inbred seed. MVF can also enhance gain by frequently adjusting the clone mix when additional data are available from the clonally replicated test. On the other hand, the gains in the orchard options may be overestimated as they were calculated under ideal conditions, e.g., no pollen contamination, random mating, etc. (ZOBEL and TALBERT, 1984). Other than superiority in genetic gain, MVF showed a time gain to be made by deploying superior genotypes to plantations earlier than the orchard options (MATHESON and LINDGREN, 1985), i.e., about 5 years earlier per generation for spruce species in NB (Table 1).

The specific family size and clone-by-ramet per clone combination (Table 2 ) in the current study were selected to reflect the optimal testing effort for both tests of seedlings (WHITE et al., 2007) and of clonal replicates
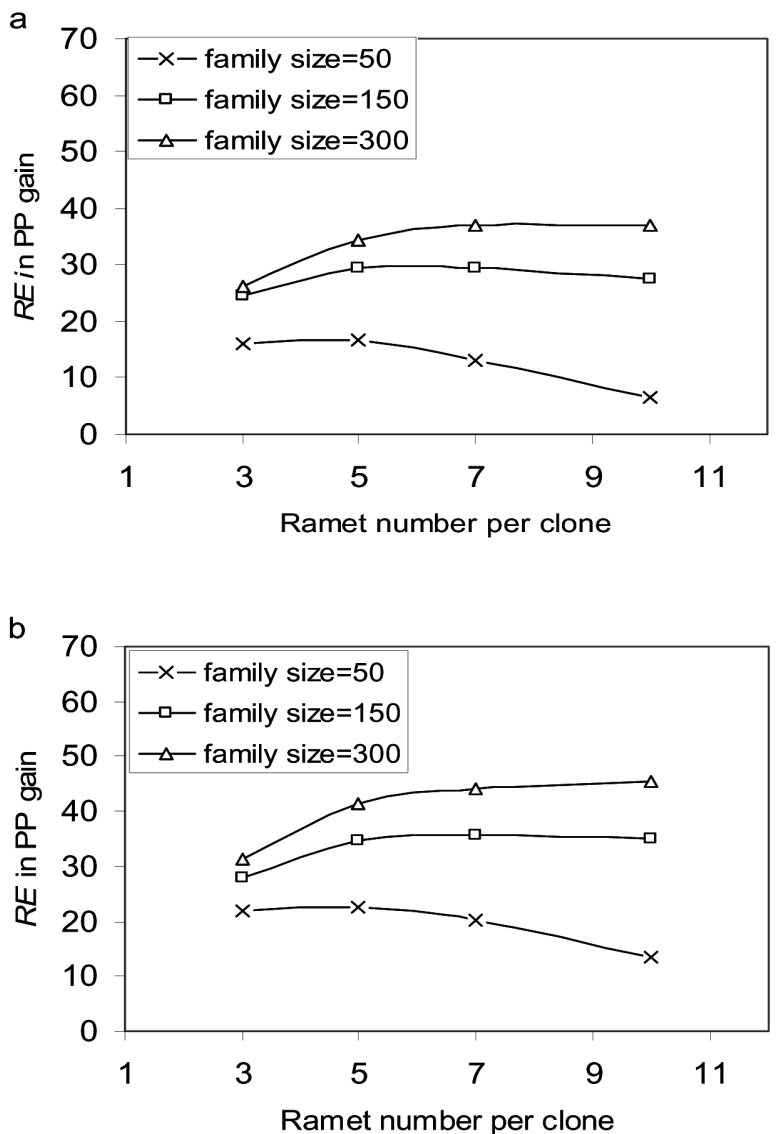

Figure 4. - Effects of family size (= clone number*ramet number per clone) and clone-by-ramet number redistribution on the relative gain efficiencies in the $5^{\text {th }}$ generation of: (a) the CSO_CRT (clonally replicated test paired with clonal seed orchard approach) and (b) MVF (clonally replicated test paired with clonal mix deployment) over the CSO_ST (seedling test paired with clonal seed orchard approach).

(SHAW and Hood, 1985; RUSSELL and Loo-DinKINS, 1993; WHITE et al., 2007). Compared to a seedling test, greater advantages in BP $A$ and $\mathrm{PP}$ gain from an equivalentsized clonally replicated test are always realized when more trees per family are planted (Rosvall et al., 1998; SHELBOURNE et al., 2007). For example, under the baseline parameter scenario and planting 5 ramets per clone, there was a significant increase in $\mathrm{PP}$ gain from a family size of 50 to 150 , i.e., the $R E_{G}\left(C S O \_C R T\right)$ increased from 17 to $36 \%$ in generation 5 , but for a family size larger than 150 , the increase was relatively small (Figure 4). With a fixed family size, larger family size allows more clones per family, and then higher within-family selection intensity. However, the corresponding increases in family size in a seedling test do not give commensurate increases in selection intensity. It can also seen from Figure 4 that the clone-by-ramet number combination influenced the relative efficiency of the clonally replicated test over seedling test, but 5 to 7 ramets per clone seems to be optimal for spruce species under NB conditions. The optimum number of ramets and clones at a given resource level to maximize gain under various $h^{2}$, genetic architectures or genotype-byenvironment interaction has been well investigated (SHAW and Hood, 1985; Russell and LibBy, 1986; RusSELL and LoO-DinkINs, 1993; Rosvall et al., 1998). 
It was assumed that a seedling test costs the same testing resources as an equivalent-sized clonal test. This may be approximately true for black spruce and white spruce as their ramets can be easily and cheaply developed by somatic embryogenesis (PARK et al., 1998) but it may be an optimistic assumption for those species which are difficult to clonally propagate. In a strict sense, an economic analysis should be included in the comparison between two testing types (MULLIN, 1994; DANUSEvičIUS and LINDGREN, 2002a), but available data for this purpose are very limited in NB. An alternative is to compare relative efficiency of a seedling test with a smallersized clonally replicated test. According to the breeding strategy and the baseline parameter scenario, even if the total number of trees planted in a clonally replicated test was only $1 / 3$ of that of the seedling test, the former could still obtain larger PP gain than did the seedling test. For example, compared to the CSO_ST with a seedling test of 150 trees per family, the CSO_CRT and MVF with a clonally replicated test of 10 clones per family and 5 ramets per clone could obtain $3.6 \%$ and $32.4 \%$ more gain after one generation and $2.5 \%$ and $12.6 \%$ more in generation 5 , respectively. Thus, a genetic test of clonal replicates can reduce its cost somewhat by reducing its testing size but still maintain its superiority over seedling test.

\section{Conclusions}

This study has demonstrated the attractive benefits of using clonal replicates in spruce breeding programs for both BP and PP selections. Compared to seedling test, the main advantage of clonally replicated test is the faster accumulation of BP $A$ and then the higher gain in PPs. The actual superiority of clonally replicated test over seedling test varied with generation, $h^{2}$ or $V_{\mathrm{NA}}$. The overall results show that, for black spruce and white spruce in NB, a program using clonally replicated test for selection paired with clonal deployment can maximize genetic gain.

\section{Acknowledgements}

We would like to thank to Dr. PEngxin Lu for his valuable comments on an earlier version of the manuscript.

\section{References cited}

Burdon, R. D. and C. J. A. Shelbourne (1974): The use of vegetative propagules for genetic information. New Zealand Journal of Forest Science 4: 418-425.

Cockerham, C. C. (1967): Group inbreeding and coancestry. Genetics 56: 89-104.

DANUSEvičIUs, D. and D. LindGREN (2002a): Efficiency of selection based on phenotype, clone and progeny testing in long-term breeding. Silvae Genetica 51: 19-26.

DANusevičIUs, D. and D. LindGren (2002b): Two-stage selection strategies in tree breeding considering gain, diversity, time and cost. Forest Genetics 9: 145-157.

DANUSEvičIUS, D. and D. LINDGREN (2005): Optimation of breeding population size for long-term breeding. Scandinavian Journal of Forest Research 20: 18-25.
FALCONER, D. S. and T. F. C. MACKAY (1996): Introduction to quantitative genetics. Longman Group Ltd., London, UK. 464pp.

FowleR, D. P. (1986): Strategies for the genetic improvement of important tree species in the Maritimes. Canadian Forest Service, Maritimes Forest Research Centre, Information Report M-X-156. Fredericton, New Brunswick.

LstibŮREK, M., T. J. Mullin, D. Lindgren and O. Rosvall (2004a): Open-nucleus breeding strategies compared with population-wide positive assortative mating. II. Unequal distribution of testing effort. Theoretical and Applied Genetics 109: 1169-1177.

LstibŮReK, M., T. J. Mullin, D. Lindgren and O. Rosvall (2004b): Open-nucleus breeding strategies compared with population-wide positive assortative mating. I. Equal distribution of testing effort. Theoretical and Applied Genetics 109: 1196-1203.

LiBBY, W. J. (1964): Clonal option and an alternative seed orchard scheme. Silvae Genetica 13: 32-40.

LIBBY, W. J. (1969): Some possibilities of the clone in forest genetics research. In: Genetics lectures. Vol. I. Edited by Bongart, R. Genetics Institute, Oregon State University, Corvallis, Oregon. pp. 121-136.

Lindgren, D., L. D. GeA and P. A. JefFerson (1996): Loss of genetic diversity monitored by status number. Silvae Genetica 45: 52-59.

Matheson, A. C. and D. Lindgren (1985): Gains from the clonal and the clonal seed orchard options compared for tree breeding programs. Theoretical and Applied Genetics 71: 242-249.

Morgenstern, E. K. and Y. S PARK (1991): Breeding of Picea mariana (Mill) B.S.P.: seed orchard and clonal approaches. Silva Fennica 25: 280-285.

MulLIN, T. J. (1994): Evaluating the economics of alternative breeding and deployment strategies for Northeastern conifers, pp. 82-105. In: Proceedings of the $24^{\text {th }}$ Meeting of the Canadian Tree Improvement Association, Part 2, 9-12 August 1993, Fredericton, NB. Natural Resources Canada, Fredericton, NB.

MULLIN, T. J. and Y. S. PARK (1995): Stochastic simulation of population management strategies for tree breeding: a new decision-support tool for personal computers. Silvae Genetica 44: 132-141.

Mullin, T. J., E. K. Morgenstern, Y. S. Park and D. P. Fowlen (1992): Genetic parameters from a clonally replicated test of black spruce (Picea mariana). Canadian Journal of Forest Research 22: 24-36.

Mullin, T. J. and Y. S. PARK (1994): Genetic parameters and age-age correlations in a clonally replicated test of black spruce after 10 years. Canadian Journal of Forest Research 24: 2330-2341.

[NBTIC] New Brunswick Tree Improvement Council (1999): Black spruce clonal test. Establishment Report No. 57. Fredericton, NB.

PARK, Y. S., J. M. BongA and T. J. Mullin (1998): Clonal forestry. Pp 143-167. In: Forest genetics and tree breeding, edited by A. K. MANDAL and GiBSON, G. L., CBS Publishers \& Distributors. Daryaganj, New Delhi. India.

Park, Y. S., J. D. Simpson, G. W. Adams, E. K., MorgenSTERN and T. J. MULLIN (1993): An updated breeding strategy for black spruce (Picea mariana (MiLL) B.S.P.) in New Brunswick, pp. 41-54. In: Breeding strategies of important tree species in Canada, edited by Y. S. PARK and G. W. ADAMS. Information Report M-X-186E. Fredericton, NB. 
Rosvall, O., D. Lindgren and T. J. Mullin (1998): Sustainability robustness and efficiency of a multi-generation breeding strategy based on within-family clonal selection. Silvae Genetica 47: 307-321.

Rosvall, O. and T. J. Mullin (2003): Positive assortative mating with selection restrictions on group coancestry enhances gain while conserving genetic diversity in long-term forest tree breeding. Theoretical and Applied Genetics 107: 629-642.

Russell, J. H. and J. A. Loo-Dinkins (1993): Distribution of testing effort in cloned genetic tests. Silvae Genetica 42: 98-104.

Russell, J. H. and W. J. LiBBY (1986): Clonal testing efficiency: the trade-offs between clones tested and ramets per clone. Canadian Journal of Forest Research 16: 9259302.

SHAW, D. V. and J. V. HooD (1985): Maximizing gain per effort by using clonal replicates in genetic tests. Theoretical and Applied Genetics 71: 392-399.

Shelbourne, C. J. A. (1992): Genetic gains from different kinds of breeding population and seed or plant production population. South African Forestry Journal 160: 49-65.
Shelbourne, C. J. A., S. Kumar, R. D. Burdon, L. D. Gea and H. S. Dungey (2007): Deterministic simulation of gains for seedling and cloned main and elite breeding populations of Pinus radiata and implications for strategy. Silvae Genetica 56: 259-270.

Weng, Y. H., K. J. Tosh, Y. S. PARK and M. S. Fullarton (2007): Application of nursery testing in long-term white spruce improvement programs. Northern Journal of Applied Forestry 24: 296-300.

Weng, Y. H., Y. S. Park, M. J. Krasowski, K. J. Tosh and G. ADAMS (2008): Partitioning of genetic variance and selection efficiency for alternative vegetative deployment strategies for white spruce in Eastern Canada. Tree Genetics and Genomes 4: 809-819.

White, T. L., W. T. Adams and D. B. Neale (2007): Forest genetics. CABI Publishing, Cambridge, MA, USA. $682 \mathrm{pp}$.

ZoBel, B. J. and J. T. TALBERT (1984): Applied forest tree improvement. John Wiley \& Sons. New York, USA. 505pp. 